\title{
IMPLEMENTASI SISTEM KLAIM ASURANSI KENDARAAN BERMOTOR DI PT. IBS INSURANCE BROKING SERVICE, JAKARTA BERBASIS MOBILE
}

\author{
Christine Dewi ${ }^{1}$ \\ Kevin Hasudungan Brotosetyo Putro ${ }^{2}$ \\ Ramos Somya ${ }^{3}$ \\ Staff Pengajar Fakultas Teknologi Informasi, Universitas Kristen Satya Wacana \\ Salatiga ${ }^{1}$,Mahasiswa Fakultas Teknologi Informasi Jurusan Teknik Informatika, \\ Universitas Kristen Satya Wacana Salatiga ${ }^{2}$,Staff Pengajar Fakultas Teknologi Informasi, \\ Universitas Kristen Satya Wacana Salatiga ${ }^{3}$ \\ e-mail :christine.dewi@staff.uksw.edu, kevinhbp@gmail, ramos.6005@gmail.com
}

Diterima:02 Oktober 2015 / Disetujui : 12 November 2015

\begin{abstract}
Claim's services in the PT. IBS Insurance Broking Service experiencing some obstacles in handling claim report. Claim officer cannot send notification letter and claim form to client who has not been having facsimile machine, error form filling, resulting the client must resend a new claim form, claim officer cannot quickly having assessment process permission. Therefore, a new system is needed to solve the claim activities problems. Claim system development aim to help claim officers to do their claim process. Analyzing claim process, system designing, implementing new system and testing new system, also analyzing test result, and writing research result are needed to develop new claim system. Claim applications created with Google Cloud Messaging Service, FPDF library, PHPExcel library, and REST Web Service. This research generates claim system helped with application based on mobile android platform. This research's result shows the new system help client, claim officer, assessment officer, and claim head to do his/her job in the claim process.
\end{abstract}

Keyword :Claim, Android platform, Google Cloud Messaging, FPDF library, PHPExcel library, REST Web Service.

\begin{abstract}
ABSTRAK
Layanan klaim PT. IBS Insurance Broking Service saat ini mengalami kendala dalam proses penanganan laporan klaim. Petugas klaim tidak dapat mengirimkan surat pemberitahuan dan formulir klaim kepada pelanggan yang belum memiliki mesin facsimile, kesalahan pengisian formulir seperti tidak jelas atau kurang, petugas klaim tidak dapat meminta persetujuan proses perbaikan kepada kepala bagian. Untuk itu dibutuhkan sistem klaim yang dapat menyelesaikan masalah proses klaim. Untuk mengembangkan sistem klaim baru dilakukan analisa proses klaim, perancangan sistem, implementasi dan pengujian sistem, serta analisa hasil pengujian, dan penulisan laporan hasil penelitian. Pengembangan sistem klaim bertujuan untuk meringankan pekerjaan petugas klaim pada proses klaim. Aplikasi Klaim dibangun memanfaatkan layanan Google Cloud Messaging, serta teknologi library FPDF, library PHPExcel, dan REST Web Service.Penelitian ini menghasilkan sistem klaim dengan bantuan aplikasi berbasis mobile pada platform Android. Hasil penelitian menunjukan sistem klaim baru dapat membantu pelanggan, petugas klaim, petugas pengecekan, dan kepala klaim dalam melakukan tugasnya dalam proses klaim.
\end{abstract}


Kata Kunci :Klaim, Platform Android, Google Cloud Messaging, library FPDF, library PHPExcel, REST Web Service.

\section{PENDAHULUAN}

PT. IBS Insurance Broking Service merupakan salah satu perusahaan yang bergerak pada bidang asuransi.PT.IBS Insurance Broking Service memberikan jasa manajemen resiko dan asuransi yang disesuaikan dengan kebutuhan setiap pelanggan.PT.IBS Insurance Broking Service mengembangkan kelompok layanan terpadu pada setiap industri kunci salah satunya adalah industri menengah, dan afinitas kecil, yang menangani asuransi kendaraan bermotor. Proses klaim asuransi kendaraan bermotor akan ditangani oleh tim klaim khusus yang hanya melayani klaim asuransi kendaraan bermotor.

Pada proses klaim asuransi kendaraan bermotor di PT. IBS Insurance Broking Service kegiatan yang terjadi pada umumnya, pelanggan melaporkan kejadian yang terjadi kepada bagian klaim menggunakan telepon. Petugas klaim menggunakan kode sertifikat polis dari pelanggan untuk melihat data pelanggan didalam fileexcel. Petugas klaim membuat surat pemberitahuan, mengenai dokumen yang harus dikumpulkan dan diserahkan pelanggan kepada manajemen klaim. Petugas klaim mengirim surat pemberitahuan ini bersama dengan formulirklaim melalui facsimile. Petugas klaim membuat surat pengecekan kendaraan bermotor dan meminta persetujuan kepada kepala klaim, untuk memulai proses pengecekan kendaraan. Kepala klaim memberikan persetujuan kepada petugas klaim melalui surat pemberitahuan pengecekan kendaraan. Petugas klaim mengirimkan surat pemberitahuan pengecekan kendaraan kepada pelanggan. Pelanggan membawa kendaraan bermotor ke bengkel resmi yang telah ditunjuk perusahaan.Petugas pengecekan mengecek kendaraan.Petugas pengecekan melaporankan pengecekan kepada petugas klaim. Dari hasil wawancara dengan pelanggan, petugas klaim, petugas pengecekan, dan kepala bagian klaim, kendala yang masih dialami untuk proses yang ada saat ini yaitu 1) kesalahan pengisian formulir atau adanya bagian formulir yang tidak diisi atau pengisian formulir yang tidak jelas, 2) petugas klaim kesulitan mengirimkan surat pemberitahuan dan formulir klaim, jika pelanggan tidak memiliki facsimile, 3) proses klaim menjadi lama, karena apabila terdapat kesalahan isi formulir atau isian formulir yang tidak jelas, proses pengumpulan dokumen formulir klaim akan diulangi, 4) proses klaim akan menjadi lama, jika petugas klaim tidak dapat menemui kepala klaim untuk meminta tanda tangan sebagai persetujuan formal proses perbaikan, 5) pelanggan kesulitan mendapatkan informasi status klaim dan keterangan proses klaim, jika petugas klaim tidak dapat mengingat informasi, kondisi dan lokasi kendaraan.

Dibutuhkan sebuah sistem yang dapat memecahkan masalah proses klaim. Perancangan sebuah aplikasi berbasis mobile dapat membantu pelanggan dalam mengisi formulir laporan klaim secara rapi dan mengetahui status perubahan laporan klaim secara cepat, memudahkan petugas klaim mengelola data laporan klaim, memudahkan petugas klaim mengirimkan keterangan proses klaim yang berlangsung, memudahkan petugas pengecekan mendapatkan informasi keadaan kendaraan bermotor, memudahkan petugas pengecekan mengirimkan informasi pengecekan kepada petugas klaim dan pelanggan, dan memudahkan kepala bagian klaim memberikan persetujuannya kepada petugas klaim untuk memulai proses pengecekan kendaraan bermotor. 
Aplikasi yang akan dibuat berbasis mobile dengan platform Android karena sebagian besar pelanggan, petugas klaim, petugas pengecekan, dan kepala klaim menggunakan smartphone Android, dan karena sistem operasi perangkat mobile Android merupakan sistem operasi yang paling banyak digunakan di dunia [1]. Versi Android yang digunakan adalah versi 3.0 atau yang lebih baru karena aplikasi dibuat dengan fungsi yang ada pada API Android versi 11. Aplikasi akan dibuat dengan memanfaatkan layanan Google Cloud Messaging, serta library FPDF, library PHPExcel, dan REST Web Service. Sistem tidak mencakup sistem pada bengkel dan proses keuangan klaim. Sistem akan dibuat dengan acuan IBS Claims Management Group Procedure and Guidelines 2013.

Berdasarkan latar belakang yang telah dipaparkan, maka dalam penelitian ini terdapat rumusan masalah yaitu bagaimana merancang dan mengimplementasikan sistem klaim asuransi kendaraan bermotor berbasis mobile pada platform Android dengan studi kasus pada PT. IBS Insurance Broking Service, Jakarta. Rumusan masalah akan digunakan sebagai pedoman untuk mencapai tujuan penelitian yaitu merancang sebuah sistem baru yang dapat membantu sistem kerja proses klaim dan kemudian diimplementasikan ke dalam sebuah aplikasi klaim berbasis mobile dengan platform Android. Manfaat dari pembuatan sistem klaim ini yaitu membantu proses pengiriman email pemberitahuan proses klaim kepada pelanggan, membantu proses pengiriman formulir klaim kepada pelanggan, membantu proses pemberitahuan perubahan status laporan kepada pelanggan, membantu proses pemberitahuan keterangan proses klaim kepada pelanggan, membantu proses persetujuan klaim oleh kepala bagian.

\section{KAJIAN PUSTAKA}

Salah satu penelitian yang pernah menggunakan layanan Google Cloud Messaging sebelumnya adalah penelitian yang berjudul "Perancangan dan Pengimplementasian

SalesMobileApplication Menggunakan Teknologi Location Based Service dan Google Cloud Messaging (Studi Kasus: PT. Armada Internasional Motor, Magelang)”. Penelitian ini telah membahas mengenai pembuatan aplikasi pada smartphone yang berguna memberikan cara kepada sales untuk mendapatkan data terbaru pada database secara cepat dan praktis sehingga kegiatan penjualan kepada pelanggan berjalan lebih cepat. Sales dapat mengetahui informasi barang dan data persediaan yang tersedia tanpa harus menghubungi gudang perusahaan, sales juga secara cepat mengumpulkan persetujuan dari supervisor sales, administration head, dan kepala cabang tanpa harus bertatap muka langsung untuk dapat menyelesaikan permintaan barang.Data penjualan dapat tersimpan rapi, sehingga sales dapat membuat laporan penjualan dengan cepat dan rapi [2]. Penggunaan layanan Google Cloud Messaging untuk permintaan persetujuan, serta proses permintaan persetujuan pada penelitian ini menjadi acuan untuk merancang proses permintaan persetujuan klaim penelitian yang akan dilakukan. Layanan Google Cloud Messaging juga diterapkan pada proses pemberitahuan informasi klaim yang dapat membantu pelanggan, petugas klaim, petugas pengecekan mengetahui perubahan status klaim.

Penelitian lain yang berjudul "Sistem Informasi Klaim Asuransi Kendaraan Bermotor Berbasis Web Pada PT. Asuransi Bangun Persada Askrida Cabang Bandung", telah membahas tentang bagaimana memberikan cara kepada pelanggan, untuk dapat melakukan pendaftaran klaim asuransi secara cepat. Penelitian ini bertujuan untuk memberikan 
cara cepat pelanggan untuk melakukan pengisian formulir pendaftaran klaim, dan membantu petugas klaim dalam mendapatkan informasi klaim [3]. Proses pengisian formulir pada penelitian ini juga menjadi acuan pengisian formulir klaim pada penelitian yang akan dilakukan. Proses pengisian dibantu dengan aplikasi mobile yang sanggup memberitahu kesalahan pengisian seperti terdapat isian yang harus diisi namun belum diisi. Proses pengisian dibantu dengan teknologi library FPDF sehingga pelanggan dapat memiliki filepdf dari formulir klaim yang diisi dengan pengisian yang telah dilakukan di aplikasi mobile.

Berdasarkan penelitian-penelitian yang telah dilakukan terkait sistem klaim dan sistem dengan platformmobile, maka dilakukan penelitian yang membahas tentang perancangan dan pengimplementasian aplikasi klaim berbasis mobile dengan platform Android.Aplikasi mobile yang dibangun menggunakan layanan Google Cloud Messaging, serta teknologi library FPDF, library PHPExcel,dan RESTWeb Service.

Google Cloud Messaging adalah suatu layanan yang memungkinkan pengembang aplikasi untuk mengirim data dari server ke aplikasi Android secara realtime.Layanan ini menyediakan sebuah mekanisme sederhana yang tidak memakan banyak sumber daya CPU yang memungkinkan server untuk melakukan kontak terhadap aplikasi mobile pada sistem operasi Android agar aplikasi tersebut segera mengambil data terbaru pada server [4].Layanan Google Cloud Messaging adalah suatu layanan yang berguna mengirimkan data pesan singkat dari server ke perangkat Android.Google Cloud Messaging dapat mengirimkan pesan singkat untuk memberitahukan aplikasi bahwa terdapat data baru yang akan diambil dari server. Layanan Google Cloud Messaging diterapkan pada aplikasi dalam bentuk notifikasi atau pesan singkat yang dikirimkan oleh server saat terdapat permintaan klaim masuk, perubahan status klaim, dan perubahan petugas yang menangani klaim. Notifikasi ini digunakan untuk memberikan informasi kepada petugas klaim dan kepala bagian klaim ketika pelanggan melakukan permintaan proses klaim yang membutuhkan persetujuan dari pihak-pihak tersebut. [5]

Web Service merupakan sebuah aplikasi di internet yang dapat diakses oleh aplikasi yang lain melalui web yang tidak terikat oleh suatu bahasa pemrograman dan atau suatu sistem operasi. WebService merupakan middleware internet yang memungkinkan berbagai sistem untuk saling berkomunikasi tanpa terpengaruh pada platform [6].Teknologi Web Service digunakan untuk mengirim data atau pesan di dalam format tertentu yang dikirim oleh salah satu pihak ke server maupun dari server.RESTWeb Service adalah salah satu gaya arsitektur yang diterapkan di dalam metode pertukaran data Web Service. RESTWeb Service diakses menggunakan alamat web, dengan konten pesan yang terformat. Penggunaan format JavaScript Object Notation (JSON) sebagai format pesan di dalam RESTWeb Service dapat meningkatkan performa pertukaran data, karena format JSON relatif berukuran lebih kecil dibandingkan dengan format $X M L$ atau format data yang lain. Pada penelitian ini RESTWeb Service digunakan untuk mengirim data dari server ke perangkat mobile [7].

JavaScript Object Notation (JSON) merupakan sebuah format data yang sederhana, ringan, dan dapat merepresentasikan data nested, dan data terstruktur serta dapat dibaca dan ditulis oleh banyak bahasa pemrograman yang ada saat ini. JSON tidak mementingkan tipe data tertentu pada setiap data, semua data akan di anggap sebuah teks. JSON adalah format data yang sederhana, dan tidak memakan banyak tempat, maka format ini sangat cocok digunakan untuk 
mengirim data dari aplikasi mobile atau ke aplikasi mobile [8].

Format JSON tidak tergantung dengan bahasa pemograman apapun, struktur JSON sederhana sehingga mudah diimplementasikan.JSON lebih sedikit membutuhkan space dan tidak perlu dituliskan dengan lengkap layaknya XML.Sehingga secara logika, proses pengolahannya (parsing) lebih cepat [9].

\section{PERANCANGAN SISTEM}

Pada perancangan sistem dengan $U M L$ berfungsi untuk menggambarkan proses kerja dari sebuah aplikasi. Use case diagramdigunakan untuk mevisualisasikan tindakan yang dapat dilakukan oleh sebuah elemen. Use case dapat menjelaskan sistem dilihat menurut pandangan orang yang berada diluar sistem [10]. Use casediagram pada penelitian ini dibagi menjadi dua: 1) aplikasi mobile memiliki empat aktor utama yaitu pelanggan, petugas klaim, petugas pengecekan, dan kepala bagian sebagai pengguna, 2) aplikasi web memiliki seorang aktor utama yaitu admin sebagai pengguna. Use case diagram aplikasi mobile dapat dilihat padaGambar 4.

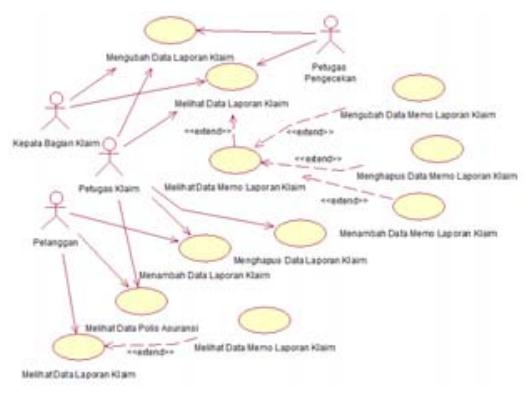

\section{Gambar 4 Use Case Diagram Aplikasi Mobile}

Gambar 4 menggambarkan use case diagram aplikasi mobile. Aplikasi klaim mobile memiliki empat pengguna, yaitu pelanggan yang dapat melihat polis asuransi, menambah laporan klaim, melihat laporan klaim, melihat memo pada laporan klaim. Petugas klaim yang dapat

Vol.9 No.2 - Januari 2016 melihat polis asuransi, melihat laporan klaim, menambah laporan klaim, mengubah laporan klaim, menghapus laporan klaim, melihat memo pada laporan klaim, menambah memo pada laporan klaim, mengubah memo pada laporan klaim, dan menghapus memo pada laporan klaim.

Petugas pengecekan dapat melihat laporan klaim, mengubah laporan klaim, melihat memo pada laporan klaim, menambah memo pada laporan klaim, mengubah memo pada laporan klaim, dan menghapus memo pada laporan klaim.Kepala bagian klaim dapat melihat laporan klaim, mengubah laporan klaim, melihat memo pada laporan klaim, menambah memo pada laporan klaim, mengubah memo pada laporan klaim, dan menghapus memo pada laporan klaim. Use case diagram aplikasi web dapat dilihat padaGambar 5.

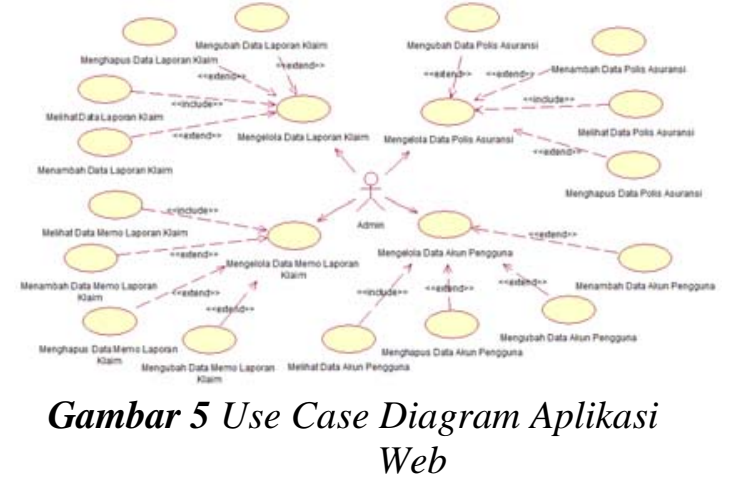

Gambar 5 adalah use case diagram aplikasi web. Aplikasi klaim web memiliki seorang pengguna, yaitu admin yang dapat melihat akun pengguna, menambah akun pengguna, mengubah akun pengguna, menghapus akun pengguna, melihat polis asuransi, menambah polis asuransi, mengubah polis asuransi, menghapus polis asuransi, melihat laporan klaim, menambah laporan klaim, mengubah laporan klaim, menghapus laporan klaim, melihat memo pada laporan klaim, menambah memo pada laporan klaim, mengubah memo pada laporan klaim, dan menghapus memo pada laporan klaim. Aplikasi web admin dapat membaca file excel polis asuransi yang merupakan 
tempat penyimpanan data pelanggan dan polis asuransi yang dimiliki pelanggan, sehingga sistem dapat membantu admin memasukan data pelanggan dan data polis pelanggan dengan menggunakan file excel. Aplikasi web diterapkan pada server lokal sehingga aplikasi web dapat menjadi aplikasi cadangan apabila terdapat kesalahan aplikasi mobile. Admin dapat memberikan akses kepada petugas klaim yang akan menangani proses klaim. Activity diagram menggambarkan aliran kontrol dari aktifitas ke aktifitas, aktifitas berkembang menjadi pengeksekusian aksi mandiri. Activity diagram juga menampilkan decision yang mungkin terjadi dan bagaimana mereka berakhir [10].

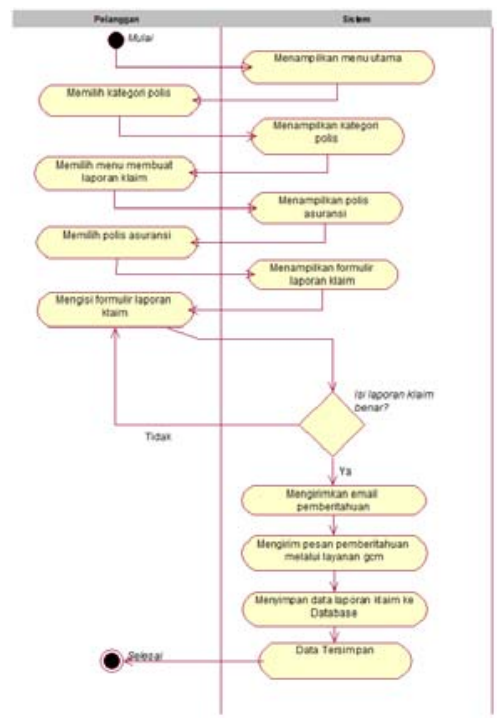

Gambar 6 Activity Diagram Penambahan Laporan Klaim oleh Pelanggan

Gambar 6 dijelaskan untuk penambahan laporan klaim oleh pelanggan, saat pelanggan ditampilkan menu utama, pelanggan harus memilih menu membuat laporan klaim. Pelanggan lalu memilih kategori polis auto, kemudian memilih polis asuransi yang akan dilaporkan, kemudian pelanggan diwajibkan mengisi formulir laporan klaim, bila pengisian benar maka pelanggan akan menerima notifikasi google cloud messaging bahwa email pemberitahuan beserta formulir laporan klaim yang sudah terisi telah dikirim ke alamat email pelanggan, dan data laporan klaim disimpan ke database. Class diagram menggambarkan struktur dan deskripsi class, package dan objek beserta hubungan satu sama lain seperti, pewarisan, dan asosiasi [10].

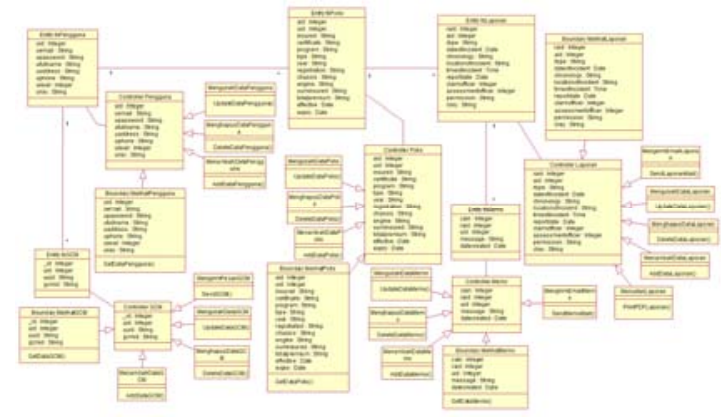

Gambar 7 Class Diagram Sistem Klaim

Gambar 7 class diagram tersebut menunjukan hubungan antar module pada aplikasi sistem klaim. Class diagram menggambarkan database yang akan dibuat dan interaksi yang mungkin terjadi. Pada diagram tersebut terdapat lima tabel yang saling terhubung dan aktifitas yang dapat dilakukan seperti melihat data, menghapus data, menambah data, dan mengubah data, mengirim pesan $G C M$, mengirim email. Deployment diagram adalah susunan fisik sebuah sistem, menunjukkan tata letak bagian-bagian software yang berjalan pada bagian-bagian hardware [10]. Deployment diagram pada aplikasi ini dapat dilihat pada Gambar 8.

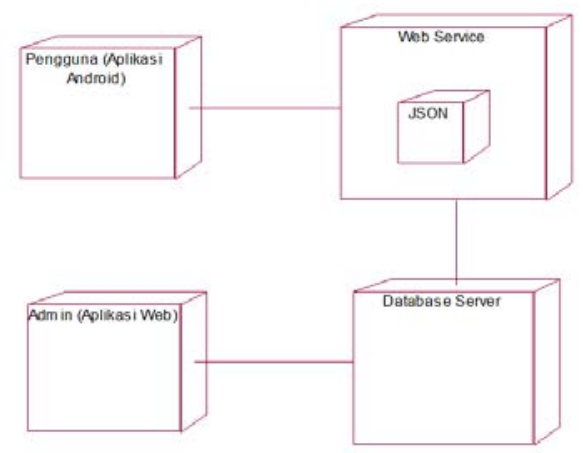

Gambar 8 Deployment Diagram

Gambar 8 menggambarkan deployment diagram dari sistem aplikasi 
klaim. Pada deployment diagram terdapat dua macam perangkat lunak yaitu aplikasi mobile dan aplikasi web. Aplikasi mobileterhubung dengan webservice, dan webservice berfungsi sebagai penghubung antara aplikasi mobile dengan database. Pada diagram ini terdapat webservice yang menggunakan bahasa pertukaran data JSON untuk akses data ke aplikasi mobile. Webservice dibangun dengan menggunakan bahasa pemrograman web yaitu PHP.Webservice ini juga terhubung dengan database pada server.Sedangkan untuk aplikasi web dapat berhubungan langsung dengan database server. Berdasarkan deployment diagram ini dirancang arsitektur sistem dari sistem aplikasi klaim.

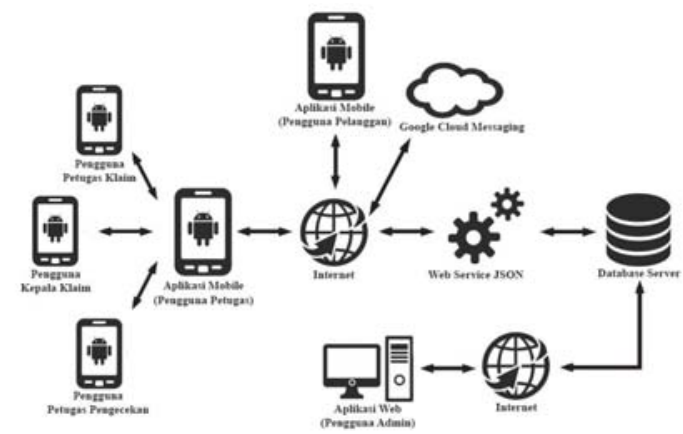

Gambar 9 Arsitektur Sistem

Pada Gambar 9 dapat dilihat terdapat 3 aplikasi dalam arsitektur ini yaitu dua aplikasi mobile dan satu aplikasi web.Aplikasi mobile diimplementasikan ke perangkat mobile dibagi menjadi dua aplikasi.Aplikasi mobile yang pertama digunakan oleh pelanggan, aplikasi mobile yang kedua digunakan oleh Petugas Klaim, Petugas Pengecekan dan Kepala Bagian Klaim. Aplikasi web diimplementasikan pada server dan ditujukan kepada admin untuk melihat dan mengelola data-data mengenai klaim.

Perangkat harus terhubung dengan koneksi internet agar aplikasi dapat berjalan.Aplikasi mobile dapat mengambil data di database server atau mengirim data ke database server melalui web serviceJSON.Layanan Google Cloud
Messagingakan berjalan secara otomatis saat aplikasi web service memanggil layanan.

\section{Hasil dan Pembahasan}

Penelitian ini menghasilkan dua aplikasi yaitu aplikasi mobile dan web.Pada aplikasi mobile diimplementasikan pada android platform sedangkan aplikasi web diimplementasikan pada server.Aplikasi mobile ditujukan kepada pelanggan yang memiliki polis asuransi di PT. IBS Insurance Broking Service Jakarta, sedangkan aplikasi web digunakan oleh administrator untuk mengelola data-data yang ada yaitu data akun pengguna, data polis asuransi, data laporan klaim dan data pengajuan klaim.

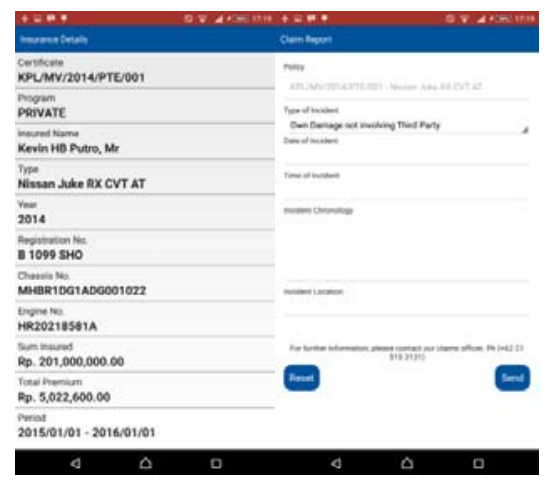

Gambar 10 Detil Polis Asuransi (Kiri), Formulir Laporan Klaim (Kanan)

Gambar 10 adalah halaman pada aplikasi mobile pelanggan. Pada aplikasi mobile pelanggan dapat melihat detil polis asuransi yang dimiliki, serta menambah laporan klaim menggunakan isian yang sudah disesuaikan dengan formulir laporan klaim asli. Pelanggan tidak perlu memasukan isian keterangan polis seperti sertifikat polis ke dalam formulir polis, pelanggan hanya perlu memasukan isian bagian keterangan laporan.

Kode Program 1 Mengirimkan Email Pemberitahuan Penambahan Laporan Klaim 
Kode Program 1 adalah Kode

Program untuk mengirimkan email pemberitahuan kepada pelanggan dan kepada petugas klaim. Ketika pelanggan submit laporan klaim, sistem akan mengirim pesan email yang telah terformat sesuai dengan tujuan pesan. Sistem akan mengirim dua tipe pesan email pemberitahuan yaitu tipe pemberitahuan proses klaim selanjutnya kepada pelanggan, dan tipe laporan klaim baru kepada semua petugas klaim. Sistem akan mencari alamat email akun yang memiliki peran sebagai petugas klaim di database.Pada Kode Program 1, baris 6 terdapat kode opsi mengubah format email menjadi format HTML, kode opsi ini kemudian akan diikutkan kedalam fungsi yang dimiliki $P H P$ untuk mengirim pesan email tanpa tambahan library pada baris 11, 12, dan 13.

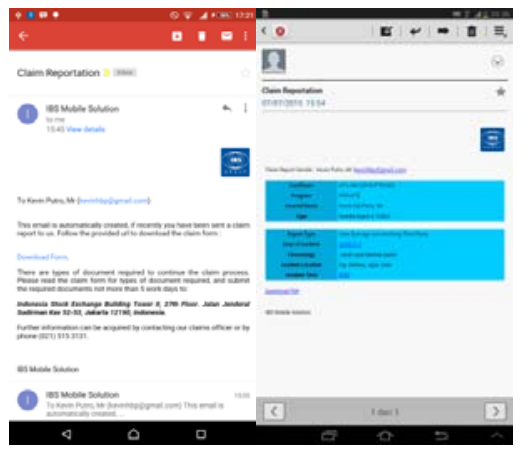

Gambar 11 Email Pelanggan (Kiri), dan Email Petugas Klaim (Kanan)

Gambar 11 merupakan email yang diterima oleh pelanggan dan petugas klaim. Pelanggan dan Petugas Klaim akan menerima email pemberitahuan yang berbeda namun pada semua pesan email telah beserta tautan untuk mengunduh file pdf laporan klaim. File PDF laporan klaim telah disesuaikan dengan formulir klaim versi perusahaan.

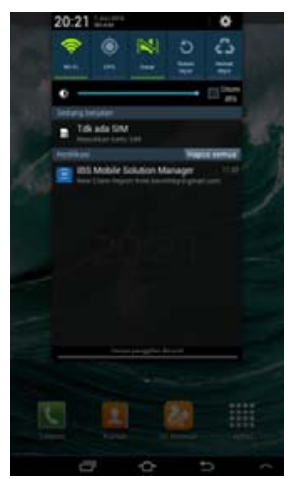

\section{Gambar 12 Pesan GCM}

Gambar 12 merupakan gambar pesan GCM yang diterima oleh perangkat genggam.Aplikasi mobile semua user memiliki kemampuan untuk membantu pelanggan, petugas klaim, petugas pengecekan, dan kepala bagian klaim untuk mendapatkan pesan notifikasi dari layanan GCM. Pesan GCM dikirimkan oleh web service yang terhubung dengan server layanan GCM, ketika terdapat aksi yang membutuhkan mengirimkan pesan pemberitahuan melalui GCM kepada perangkat genggam terkait, seperti perangkat genggam pelanggan yang melaporkan laporan klaim, perangkat petugas klaim saat terdapat laporan klaim baru, perangkat genggam

Kode Program 2 Mengirimkan Pesan GCM

Kode Program 2 adalah fungsi $P H P$ yang digunakan oleh aplikasi mobile untuk mengirimkan pesan GCM. Diperlukan GoogleAPIKey, id GCM, dan isi pesan agar Kode Program 2 dapat berjalan dan sistem dapat melakukan notifikasi. Google 
API Key didapatkan melalui proses pendaftaran aplikasi ke server GCM, id GCM bersifat unique, didapatkan melalui proses pendaftaran device ke serverGCM.

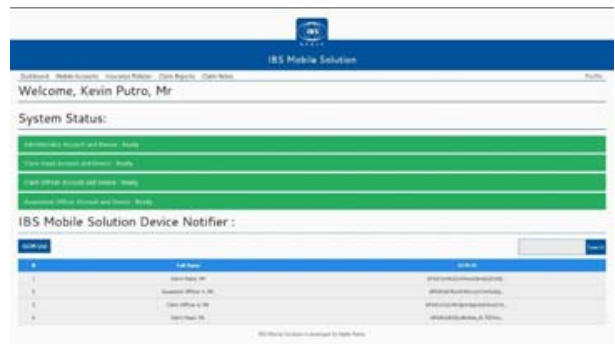

\section{Gambar 13 Halaman Administrator}

Gambar 13 merupakan halaman administrator.Administrator menggunakan aplikasi web untuk mengelola data akun pengguna aplikasi dan data polis asuransi pengguna sistem klaim mobile.Administrator dapat mengetahui status status akun petugas klaim, status akun petugas pengecekan, dan status akun kepala bagian klaim.Administrator dapat memasukan data akun yang berupa file excel atau csvuntuk dimasukan kedalam database melalui library PHPExcel. Halaman administrator juga dapat mengelola data laporan klaim, dan memo laporan klaim, agar dapat menopang aplikasi mobile yang digunakan oleh petugas klaim, petugas pengecekan, dan kepala klaim jika terjadi kesalahan koneksi antara aplikasi mobile dengan server.

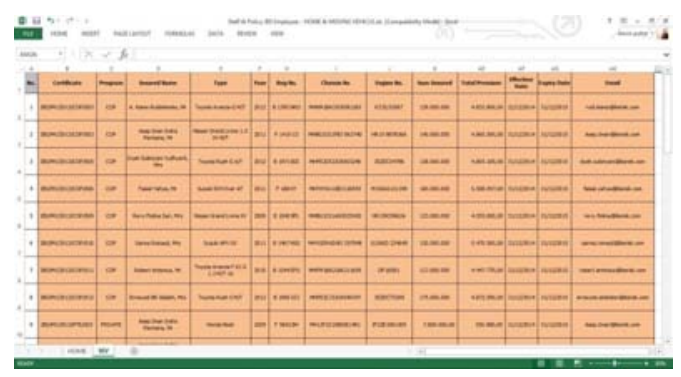

Gambar 14 Data Polis Asuransi Kendaraan Bermotor
Gambar 14 merupakan data polis asuransi kendaraan bermotor di dalam file excel. Petugas klaim menggunakan file ini untuk mendapatkan informasi polis asuransi kendaraan bermotor pelanggan. Di dalam sistem baru file excel seperti Gambar 14 dapat digunakan untuk memasukan data polis ke database. Membaca file excel dibutuhkan library PHPExcel karena PHP tidak dapat membaca file excel.

\section{Kode Program 3 Membaca File CSV}

Kode Program 3 adalah Kode Program untuk membaca file Untuk membaca file excel, file excel akan terlebih dahulu diformatke format csv, kemudian format csv akan dapat dibaca oleh PHP dengan bantuan library PHPExcel. Pada Kode Program 3, baris 12 data yang dibaca akan menjadi array data.

Pengujian aplikasi dilakukan untuk menguji fungsi dari setiap fitur yang ada. Pengujian dilakukan dengan dua cara, yaitu alfa dan beta. Pengujian alfa adalah pengujian yang dilakukan oleh programmer terhadap aplikasi yang dibuat sebelum aplikasi tersebut diujikan kepada user.

Tabel 1 Hasil Pengujian Fungsionalitas

\begin{tabular}{lllll}
\hline $\begin{array}{l}\text { Modul yang } \\
\text { diuji }\end{array}$ & $\begin{array}{l}\text { Data } \\
\text { Input } \\
\text { Kondisi }\end{array}$ & & Hasil Uji & Status \\
& & & \\
\hline 1 & Penambahan & Pengisian & Penambahan & Valid \\
& Laporan & form & Sukses, Email & \\
& Klaim & Benar & pemberitahua & \\
& & n dan pesan & \\
& & & $G C M$ terkirim & \\
& & &
\end{tabular}




\begin{tabular}{|c|c|c|c|c|}
\hline & & $\begin{array}{l}\text { Pengisian } \\
\text { form } \\
\text { Salah }\end{array}$ & $\begin{array}{l}\text { Pendaftaran } \\
\text { gagal, Email } \\
\text { pemberitahua } \\
\text { n dan pesan } \\
G C M \text { tidak } \\
\text { terkirim }\end{array}$ & Valid \\
\hline \multirow[t]{2}{*}{2} & $\begin{array}{l}\text { Pengubahan } \\
\text { Laporan } \\
\text { Klaim }\end{array}$ & $\begin{array}{l}\text { Pengisian } \\
\text { form } \\
\text { Benar }\end{array}$ & $\begin{array}{l}\text { Data laporan } \\
\text { klaim berhasil } \\
\text { diubah, pesan } \\
\text { GCM terkirim }\end{array}$ & Valid \\
\hline & & $\begin{array}{l}\text { Pengisian } \\
\text { form } \\
\text { Salah }\end{array}$ & $\begin{array}{l}\text { Data laporan } \\
\text { klaim gagal } \\
\text { diubah, pesan } \\
G C M \text { tidak } \\
\text { terkirim }\end{array}$ & Valid \\
\hline 3 & $\begin{array}{l}\text { Penambahan } \\
\text { Memo } \\
\text { Laporan } \\
\text { Klaim }\end{array}$ & $\begin{array}{l}\text { Pengisian } \\
\text { form } \\
\text { Benar }\end{array}$ & $\begin{array}{l}\text { Penambahan } \\
\text { Sukses, Email } \\
\text { pemberitahua } \\
\text { n dan pesan } \\
\text { GCM terkirim }\end{array}$ & Valid \\
\hline & & $\begin{array}{l}\text { Pengisian } \\
\text { form } \\
\text { Salah }\end{array}$ & $\begin{array}{l}\text { Penambahan } \\
\text { gagal, Email } \\
\text { pemberitahua } \\
\text { n dan pesan } \\
G C M \text { tidak } \\
\text { terkirim }\end{array}$ & Valid \\
\hline & $\begin{array}{l}\text { Pengubahan } \\
\text { Memo } \\
\text { Laporan } \\
\text { Klaim }\end{array}$ & $\begin{array}{l}\text { Pengisian } \\
\text { form } \\
\text { Benar }\end{array}$ & $\begin{array}{l}\text { Data memo } \\
\text { laporan klaim } \\
\text { berhasil } \\
\text { diubah, pesan } \\
\text { GCM terkirim }\end{array}$ & Valid \\
\hline & & $\begin{array}{l}\text { Pengisian } \\
\text { form } \\
\text { Salah }\end{array}$ & $\begin{array}{l}\text { Data laporan } \\
\text { klaim gagal } \\
\text { diubah, pesan } \\
G C M \text { tidak } \\
\text { terkirim }\end{array}$ & \\
\hline \multirow[t]{2}{*}{5} & $\begin{array}{l}\text { Penginputan } \\
\text { Akun } \\
\text { Pengguna }\end{array}$ & $\begin{array}{l}\text { Pengisian } \\
\text { form } \\
\text { Benar }\end{array}$ & $\begin{array}{l}\text { Data akun } \\
\text { pengguna } \\
\text { berhasil } \\
\text { ditambah }\end{array}$ & Valid \\
\hline & & $\begin{array}{l}\text { Pengisian } \\
\text { form } \\
\text { Salah }\end{array}$ & $\begin{array}{l}\text { Data akun } \\
\text { pengguna } \\
\text { gagal } \\
\text { ditambah }\end{array}$ & \\
\hline \multirow[t]{2}{*}{6} & $\begin{array}{l}\text { Pengubahan } \\
\text { Akun } \\
\text { Pengguna }\end{array}$ & $\begin{array}{l}\text { Pengisian } \\
\text { form } \\
\text { Benar }\end{array}$ & $\begin{array}{l}\text { Data akun } \\
\text { pengguna } \\
\text { berhasil } \\
\text { diubah }\end{array}$ & Valid \\
\hline & & $\begin{array}{l}\text { Pengisian } \\
\text { form } \\
\text { Salah }\end{array}$ & $\begin{array}{l}\text { Data akun } \\
\text { pengguna }\end{array}$ & \\
\hline
\end{tabular}

\begin{tabular}{|c|c|c|c|c|c|}
\hline & & & & gagal diubah & \\
\hline \multirow[t]{2}{*}{7} & \multirow[t]{2}{*}{$\begin{array}{l}\text { Penginputan } \\
\text { Polis } \\
\text { Asuransi } \\
\text { Pengguna }\end{array}$} & \multicolumn{2}{|c|}{$\begin{array}{l}\text { Pengisian } \\
\text { form : } \\
\text { Benar }\end{array}$} & $\begin{array}{l}\text { Data polis } \\
\text { asuransi } \\
\text { pengguna } \\
\text { berhasil } \\
\text { ditambah }\end{array}$ & Valid \\
\hline & & \multicolumn{2}{|c|}{$\begin{array}{l}\text { Pengisian } \\
\text { form : } \\
\text { Salah }\end{array}$} & $\begin{array}{l}\text { Data polis } \\
\text { asuransi } \\
\text { pengguna } \\
\text { gagal } \\
\text { ditambah }\end{array}$ & \\
\hline \multirow[t]{2}{*}{8} & $\begin{array}{l}\text { Pengubahan } \\
\text { Polis } \\
\text { Asuransi } \\
\text { Pengguna }\end{array}$ & \multicolumn{2}{|c|}{$\begin{array}{l}\text { Pengisian } \\
\text { form : } \\
\text { Benar }\end{array}$} & $\begin{array}{l}\text { Data polis } \\
\text { asuransi } \\
\text { pengguna } \\
\text { berhasil } \\
\text { diubah }\end{array}$ & Valid \\
\hline & & \multicolumn{2}{|c|}{$\begin{array}{l}\text { Pengisian } \\
\text { form : } \\
\text { Salah }\end{array}$} & $\begin{array}{l}\text { Data polis } \\
\text { asuransi } \\
\text { pengguna } \\
\text { gagal diubah }\end{array}$ & \\
\hline
\end{tabular}

Berdasarkan pengujian yang telah dilakukan pada aplikasi klaim, didapatkan hasil bahwa setiap fungsi yang diuji berjalan sesuai.Dapat disimpulkan bahwa setiap fitur aplikasi berjalan dengan baik dan sesuai yang diharapkan.

Pengujian beta yaitu pengujian aplikasi yang dilakukan oleh user. Pengujian beta dilakukan dengan memberi pertanyaan kepada pengguna dalam hal ini karyawan PT. IBS Insurance Broking Service yang memiliki polis asuransi kendaraan bermotor sehingga dapat memberikan informasi dan keterangan dari sudut pandang pelanggan, petugas klaim, petugas pengecekan dan direksi PT. IBS Insurance Broking Service yang dapat memberikan informasi dan keterangan dari sudut pandang sebagai kepala bagian klaim.

Berdasarkan pengujian yang telah dilakukan diperoleh hasil bahwa tampilan aplikasi klaim dapat jelas dibaca, penggunaan aplikasi klaim pada platform Android dapat membantu pelanggan, petugas klaim, petugas pengecekan, dan 
kepala klaim dalam melakukan tugasnya, proses yang sebelumnya mencapai 13 hari dapat dilakukan hingga satu sampai dua hari lebih cepat, isian yang ada dapat dipahami dan tidak membingungkan, aplikasi ini bermanfaat untuk digunakan oleh bagian klaim PT. IBS Insurance Broking Service, dan aplikasi ini layak digunakan pada saat kegiatan laporan klaim.

\section{Simpulan}

Berdasarkan hasil penelitian dan pembahasan yang telah dilakukan tentang perancangan dan pengimplementasian aplikasi klaim asuransi kendaraan bermotor berbasis mobile pada platformAndroid, dapat disimpulkan bahwa sistem klaim yang dibantu dengan device menjawab permasalahan yang terjadi di dalam proses klaim. Kesalahan pengisian formulir dapat dihindari dengan adanya proses pengisian formulir klaim dengan aplikasi mobile. Kesulitan pengiriman surat pemberitahuan dan formulir klaim kepada pelanggan karena pelanggan tidak memiliki mesin facsimile dapat dihindari dengan sistem baru yang menggunakan teknologi Google Cloud Messaging untuk notifikasi dan pengiriman email oleh sistem. Proses yang sebelumnya dapat tertunda karena kepala bagian klaim tidak dapat ditemui, dapat diatasi dengan sistem persetujuan dengan bantuan device. Pelanggan dapat memperoleh informasi perubahan status klaim melalui aplikasi mobile.

\section{Pustaka}

[1] Refsnes Data. 2015. Mobile Devices Statistics. http://www.w3schools.com/browse rs/browsers_mobile.asp, diakses tanggal 21 Agustus 2015.

[2] Sutresno, Stephen Aprius. 2015. Perancangan dan
Pengimplementasian Sales Mobile Application Menggunakan Teknologi Location Based Service dan Google Cloud Messaging (Studi Kasus: PT. Armada Internasional Motor, Magelang). Salatiga. Fakultas Teknologi Informasi Universitas Kristen Satya Wacana.

[3] Shiddieq, Diqy Fakhrun. Marlina, Leni. 2014. Sistem Informasi Klaim Asuransi Kendaraan Bermotor Berbasis Web Pada PT. Asuransi Bangun Askrida Cabang Bandung.Bandung. Politeknik Komputer Niaga LPKIA.

[4] Antonius, Alvin, Triyanto, Dedy \& Ruslianto, Ikhwan. 2015. Penerapan Pengolahan Citra Dengan Metode Adaptive Motion Detection Algorithm Pada Sistem Kamera Keamanan Dengan Push Notification Ke Smartphone Android.Jurnal Coding Sistem Komputer Untan Volume 03, No. 2 (2015), hal 54-65.

[5] Android Developers. 2012. Google Cloud Messaging for Android.http://developer.android.c om/google/gcm/index.html, diakses tanggal 12 Juli 2015.

[6] Saputra Ragil, Ashari Ahmad, 2012. "Integrasi Laporan Demam Berdarah Dengue (DBD) Menggunakan Teknologi WebService”. Semarang: Universitas Diponegoro.

[7] Mitchell, Lorna Jane. 2013, PHP Web Services.California : O’Reilly Media, Inc.

[8] Booch, Grady., Rumbaugh, James., Jacobson, Ivar. 2005. The Unified Modeling Language User Guide Second Edition. New Jersey: Addison Wesley Professional. 
[9] Nugroho, Fuad Rajab, Syafei, Amien Wahyul, Somantri, Maman. 2013. Rancang Bangun Aplikasi Streaming Education Pada Perangkat Bergerak Berbasis Android.Transient, vol 2, no 1. Hal 33-38.

[10] Pressman, Roger S. 1997. Software Engineering: a Practitioner's Approach, Fifth Edition. New York: The McGraw- Hill Companies. 